\title{
Nipah outbreak in Kerala, South India: Ethical challenges in the deployment of healthcare workers
}

\author{
JAYAKRISHNAN THAYYIL, APARNA PADMANABHAN, ALAN GANGADHARAN, SREYA SALIM, THEJUS JAYAKRISHNAN
}

\begin{abstract}
A highly fatal emerging zoonotic virus, Nipah Virus (NiV), identified as a potential threat to global health security and declared as a candidate for bioterrorism by the World Health Organization (WHO) was first reported in the South Indian district of Kozhikode, Kerala, on May 20, 2018. Following the declaration of an outbreak, emergency control measures, contact tracing, isolation, and barrier nursing were implemented by the state health department. Since no prophylactic drugs or vaccines are available to prevent further transmission, the healthcare teams responded by initiating contact tracing and isolation, the only measures available.
\end{abstract}

There were 2642 contacts that included 40\% hospital contacts (185 doctors, 476 nurses, 344 other hospital staff). Quarantine and isolation of healthy persons, especially healthcare workers, involve certain ethical issues. We present an ethical analysis and discussion of contact tracing during the Nipah outbreak in Kerala, based on six principles of public health ethics, namely justice, beneficence and utility, respect for persons, reciprocity and solidarity.

Several knowledge gaps and ethical issues that arose should be understood and addressed in future outbreaks. Setting up decision-making systems and procedures in advance is the best way to ensure that ethically appropriate decisions will be made during such future outbreaks.

Authors: Jayakrishnan Thayyil (corresponding author drjayakrishnanthayyil@gmail.com), Additional Professor, Department of Community Medicine, and Head, UNESCO Bioethics Chair Unit, Government Medical College, Kozhikode, Kerala, INDIA; Aparna Padmanabhan (aparnapadmanabhan@gmail.com), Junior Resident, Department of Community Medicine, Government Medical College, Kozhikode, Kerala, INDIA; Alan Gangadharan (dralangangadharan@gmail.com), Junior Resident, Department of Community Medicine, Government Medical College, Kozhikode, Kerala, INDIA; Sreya Salim (sreyasalim@gmail.com), Intern, Department of Community Medicine, Government Medical College, Kozhikode, Kerala, INDIA; Thejus Jayakrishnan (thejus128@gmail.com), Resident Physician, Department Of Internal Medicine, Allegheny Health Network, Pittsburg, PA, USA.

To cite: Thayyil J, Padmanabhan A, Gangadharan A, Salim S, Jayakrishnan T. Nipah outbreak in Kerala. South India: Ethical challenges in the deployment of healthcare workers. Indian J Med Ethics. 2020 Oct-Dec;5(4) NS: 330-4. DOI:10.20529/JJME.2020.078.

Published online on July 31, 2020.

Manuscript Editor:Vijayaprasad Gopichandran

Peer Reviewers: Rakesh PS and an anonymous reviewer

○ Indian Journal of Medical Ethics 2020

\section{Introduction}

In the 21st century the world has faced several pandemic threats from emerging infectious diseases like severe acute respiratory syndrome (SARS), H1N1, Middle East respiratory syndrome (MERS) and Ebola. Infectious disease outbreaks are periods of great uncertainty and particular complexities. As events unfold, a public health response needs to be initiated quickly in the face of limited resources and capacities as well as scanty evidence, to support decisionmaking. This can generate or exacerbate social crises, weaken health systems and cause institutional disruptions $(1,2)$.

A highly fatal emerging zoonotic virus, Nipah Virus (NiV) identified as a potential threat to global health security and declared a candidate for bioterrorism by the World Health Organization (WHO), was reported for the first time in the South Indian district of Kozhikode, Kerala state, on May 20, $2018(3,4)$. The identification followed recognition of a cluster of three deaths in a family due to encephalitis. A total of 23 cases were reported including the primary case, of which 21 died with a case fatality rate of $91 \%$. The undiagnosed primary case died on May 5 and the first diagnosed index case died on May 18. The declaration of a Nipah outbreak was issued in the state on May 20. Excluding the primary case, the remaining 22 persons contracted the infection by personto-person transmission from the hospital, as a nosocomial infection. The transmission occurred in three hospitals - H1-9, $\mathrm{H} 2-10, \mathrm{H} 3-3$, totally 22 cases - one tertiary, and the other two secondary level facilities where the patients were treated $(4,5)$. Retrospectively, it was proved that the primary case contracted the infection from a Pteropus bat which is a natural reservoir of Nipah virus $(5,6)$.

Following the declaration of an outbreak, emergency control measures, including contact tracing, isolation and barrier nursing were implemented by the state health department. The disease was confirmed in the index case 15 days after the death of the primary case, who was a sibling, and individuals such as the patient's relatives and other contacts were hospitalised with similar symptoms - some succumbed subsequently. In the initial period, details on actual source and route of transmission were not clear, resulting in panic. This was evidenced by the fact that many inhabitants fled their homes in the affected area leaving the area deserted, like an undeclared lockdown. Since no prophylactic drugs or vaccines were available to prevent further transmission, the health authorities responded by initiating contact tracing, which was the only tool available. The process involves identification and assessment of contacts, monitoring them to permit rapid identification of those with concerning symptoms followed 
by prompt isolation and supportive treatment. Corresponding to the maximum incubation period of Nipah, those in contact were line listed and maintained in voluntary home quarantine for a minimum three-week period, during which they were kept under direct surveillance by district health authorities and closely monitored by the Department of Community Medicine of the regional medical college. The authors' teams were mainly involved in the process of identifying, tracing, and surveillance of contacts during the outbreak. Those healthcare workers (HCWs) who developed symptoms during this period were admitted to the designated isolation hospital and had to undergo tests for Nipah. Others who completed twenty one days of quarantine uneventfully were released without any tests for Nipah, due to their non-availability. Those quarantined included community members like family members, care takers, co-patients and patient bystanders along with HCWs involved in the care of the Nipah patients or handling of the dead bodies. In all, there were 2642 contacts including 40\% hospital contacts (6), ie, 185 doctors, 476 nurses, and 344 other hospital staff.

"The process of ethical analysis involves identifying the relevant principles, applying them to a particular situation, and making judgements about how to weigh competing principles when it is not possible to satisfy them all" (1). The central ethical dilemma, during outbreak control is to balance the freedom and liberty of individuals with the responsibility of governments to impose restrictive measures, such as isolation and quarantine, to protect the health of their citizens $(1,2)$. Quarantine of healthy persons, especially HCWs, involves certain ethical issues. HCWs involved in the Ebola outbreak in Senegal reported that quarantine had led their families to consider their jobs to be too risky, creating tensions within their households (7). During the SARS outbreak quarantined HCWs had reported stigmatisation and rejection from people in their local neighborhoods (8). HCWs also reported their being unable to resume their jobs after surveillance ended because their coworkers expressed a fear of contagion (7).

Based on the data collected during the process of contact tracing, surveillance activities during Nipah, literature review on the subject of ethical issues during outbreaks, and discussions with HCWs, this paper will discuss the ethical issues which arise in contact tracing of health care workers and their quarantine. The analysis and discussion will be under the following six principles of public health ethics namely justice, beneficence and utility, respect for persons, reciprocity and solidarity (1).This review will be relevant for addressing the gaps and formulating public health ethical guidelines in the ongoing Covid-19 pandemic.

\section{Justice}

The main safeguards available for prevention of spread of the disease were contact tracing, isolation and barrier nursing, as stated before. It was noted that during the Nipah outbreak, there was injustice by way of disparity in access to resources and information across different cadres of HCWs. The information dissemination on methods of barrier nursing, and use of personal protective equipment (PPE) was inadequate among the non-technical HCWs such as nursing assistants and housekeeping staff. These HCWs were at greater risk of contracting the Nipah virus because of concentrated exposure and the inadequate provision of information and training on protecting themselves. There were no mechanisms in place to monitor their infection prevention and control practices. Also, the HCWs in the medical college hospital were better trained to protect themselves compared to those in the secondary care facilities. During this outbreak, two nurses from peripheral health centres acquired Nipah by nosocomial infections and one died, which indicates deficiencies in the application of barrier nursing (6). While the non-hospital contacts were advised home quarantine for a period of three weeks, the HCW contacts continued to work in the hospitals. They were forced to work in the hospitals without addressing their mental stress and anxiety. This unfair treatment of one group of contacts compared to others is also a matter of injustice. Apart from being unfair, this act of forcing contact HCWs to continue working could have led to serious harm by exposing patients with other ailments to potential Nipah virus infection.

\section{Beneficence and utility}

Contrary to traditional bioethics that is concerned with the benefit of individuals, beneficence in the realm of public health ethics concerns itself with acts executed for the common benefit of all (1). The principle of utility states that actions are right insofar as they promote the wellbeing of individuals or communities. Efforts to maximise utility require a consideration of proportionality and efficiency in allocating resources to maximise benefits and minimise cost burdens $(1,2)$.

One of the important questions in the ethical analysis of benefit and utility is proportionality. In the case of Nipah, the main interventions of isolation and quarantine severely restrict the liberty of the individual. Whether this restriction is proportionate to the potential benefits is the key question of benefit and utility. The Nuffield Council's "Intervention ladder" is a tool used for ranking public health measures according to their coerciveness or intrusiveness (2). A measure at the top of the ladder in controlling Nipah is compulsory quarantine or isolation. So here, tracing of contacts among HCWs and placing them in quarantine for minimum incubation periods with restrictions on freedom of movement as a mandatory measure is highly restrictive. However Nipah being a fatal infection and the probability of transmission by person to person contact being very high, this high level of restriction can be said to be warranted to curb the infection and protect the lives of people. Therefore, though the mandatory isolation and quarantine are restrictive in terms of individual liberty, the level of restriction can be said to be proportional to the level of benefit to the community. Contact tracing breached the privacy of individuals, however tracing all contacts and placing them under surveillance was useful in the early identification of illness 
and treatment to save lives. A young nursing trainee who contracted the Nipah infection was traced and kept under surveillance. Her symptoms were identified early, she was treated and her life saved. Thus, the loss of privacy due to contact tracing can be said to be proportional to the benefit of saving the lives of those who were tracked.

Another contentious matter was the quarantining of HCWs who were in contact with Nipah patients. If the HCWs were placed under home quarantine, it would have led to a gross human resource crunch thus compromising the care provided to other patients in the healthcare facilities. Moreover, redirecting HCWs for contract tracing and surveillance of the contacts of infected persons also contributed to this scarcity of human resources. This pushed the health system to mandate that all HCWs were to be quarantined in their healthcare facility and continue to be under surveillance while continuing to discharge their duties. This could be harmful to the HCWs' own health, but it might have been justified given the major human resource crunch in the healthcare facilities. However, this matter remains contentious.

\section{Respect for persons}

During quarantine or isolation, it is important to ensure that individuals have adequate physical space, opportunities to engage in recreational activities and means to communicate with their loved ones and the outside world. Fulfilling these needs is essential to respect individual dignity. Though the HCWs were not isolated, their movements and activities outside the hospital were restricted. They suffered severe stress and anxiety. Due to the fear of death, some had even written their wills. Their appetite, sleep and social life were also affected. These were compounded by the lack of arrangements for counseling.

During outbreaks, privacy and confidentiality should be protected. Even without official authorisation, the personal information of some HCWs was leaked by the media. Thus they were identified by the public during the outbreak, exposing them to stigma, avoidance and prejudice in the community. Some reported experiencing discrimination and distancing by family members, while most of them reported facing it from friends and the community. There were reports of social boycott where staff in the public transport system were reluctant to allow them to travel with other passengers. However, their superiors and co-workers in the hospitals continued to provide support by helping them and their families. Ideally those responsible for outbreak response should take steps to prevent stigmatisation and social violence and implement a communication strategy to avoid stigmatisation (1). Unfortunately, the traditional and social media fueled panic by sensationalisation. This may have led to increased stigma and discrimination against HCWs (9).

\section{Appropriate risk communication}

The media will always play an important role in any outbreak response effort as well as in influencing community behaviours. Therefore, media ethics should be strengthened to protect the privacy and confidentiality of HCWs. Their role in educating and sensitising the community and reducing panic and the spread of incorrect rumours can be decisive. To ensure this, the media was provided with accurate and timely information about the course of the outbreak through the Director of Health Services, Kerala (DHS) who was appointed as the single spokesperson for the purpose, and noteworthy efforts were made $(5,6)$.

An important ethical principle in communication is transparency which requires that decisionmakers publicly explain the basis for decisions in a manner that is linguistically and culturally appropriate. With this in mind, Aarogya Jaagratha: "Don't panic, stay vigilant"- a social media platform was started by the Department of Health. The cyber cell of the Government of Kerala was also active in surveillance and prosecuted six cases of attempts at spreading false information during this period $(5,6)$.

Rapid data sharing does remain critical as health emergencies like Nipah unfold $(10,11)$. In the present outbreak, the rate of sharing of information about transmission, risks and prevention strategies remained inadequate among epidemiologists and officials in the state. Inappropriate communication from officials such as anticipation of a second wave of cases or expectation of multiple clusters of outbreaks created panic; but may have reflected insufficient knowledge of the disease in general. Nipah outbreaks will be sporadic and self-limiting to small geographical areas but the existing evidence and reliable modeling studies were not convincing enough for some health authorities $(7,12)$.

\section{Reciprocity}

Reciprocity consists of making a "fitting and proportional return" for contributions that people have made $(1,13)$. Individuals often assume considerable personal risk to carry out their jobs. Once a worker has taken on these risks to protect society, society has a reciprocal obligation to provide the necessary support. If the reciprocal obligations are not met, frontline workers cannot legitimately be expected to assume the significant risk of harm to themselves and their families (1, 13).

At a minimum, fulfillment of reciprocal obligations to frontline workers requires the following actions:

\section{a. Provision of accurate information}

To minimise the risk of infection they should be provided with the complete and accurate information available about the nature of the pathogen and infection control measures, updated information on the epidemiological situation at the local level, and adequate personal protective equipment. For instance, immediately after the declaration of the outbreak, a central team from the Indian Council of Medical Research and All India Institute of Medical Science were deployed to the tertiary centre, Medical College Calicut, where patients were admitted 
and conducted training of the engaged staff. This was not extended to the peripheral hospitals. Minimising the risk of infection was not properly addressed due to resource constraints and lack of prior experience.

The health authorities should arrange appropriate risk communication methods to protect all HCWs from acquiring the infection while caring for patients. It was observed by the authors that no authentic printed materials were circulated among HCWs and only a few had received any form of risk communication and training in barrier nursing even after the initial cluster of deaths. Instead most HCWs had to search for information for their own protection. The knowledge gaps of lower categories of HCWs like nursing assistants, attenders, cleaning staff who were unaware of the modes of transmission of Nipah, who did not undergo any formal training, and were unable to access medical literature, were not addressed.

\section{b. Priority access to healthcare}

Frontline workers or their immediate family members who become ill through contact with the worker, should be ensured access to the highest level of care available. This was assured through contact tracing by equipping a designated isolation Centre at Calicut Medical College. However, the psychological vulnerability and felt need for counseling were not properly addressed (14).

\section{c. Appropriate remuneration}

Government should ensure that frontline workers should be given fair remuneration for their work, paid in a timely manner. According to news reports this was done (6). Many workers involved in Nipah activity were given increments or promotions but there were complaints that a few were excluded.

\section{d. Support for reintegrating into the community}

HCWs may experience stigma and discrimination, particularly those involved in unpopular measures such as infection control or burials not conducted according to the traditional customs (1). In this case, the burials were carried out by a special team in a public grave yard without religious customs $(5,6)$. The government did make efforts to reintegrate HCWs into the community, and also sought cooperation from religious leaders $(5,6)$.

\section{e. Assistance to family members}

Assistance should be provided to families of frontline workers during their absence due to their work responsibilities or to recuperate from illness (1). Death benefits should be provided to family members of frontline workers who die in the line of duty, including volunteers or "casual workers." Of the two nurses who were infected in the present outbreak, one died and the other recovered. The deceased nurse's family was compensated and her husband was offered a government job. But In the case of a contract worker, the compensation was rejected due to non-confirmation of diagnosis. Since her death occurred before the declaration of Nipah, her samples were not tested.

In an ideal situation, it is essential that frontline workers' rights and obligations be clearly established during the pre-outbreak planning period. But in the case of Nipah, there was no preplanning period and it was an unexpected event.

\section{Solidarity}

Solidarity is a social relation in which a group, community, nation or, potentially the global community stands together, and justifies collective action in the face of a common threats $(1,15)$. The Kerala community of doctors, administrative personnel, political and religious leaders, local self-governments, and police personnel all demonstrated commendable solidarity in controlling Nipah. Largely owing to this solidarity, the outbreak was controlled in a timely fashion. The last case was reported on May 24, 2018 and the area was declared free of Nipah on July 24, 2018. The collaborative efforts of all the stakeholders including the state and central government teams were key to successfully containing the outbreak and potentially reducing costs in terms of loss of livelihood and commerce (especially given the role of the international fruit and vegetable trade in Kerala farmers' livelihoods) (5). This solidarity may also have helped limit the spread of Nipah beyond the geographical area initially affected.

\section{Summary and conclusion}

We conducted an analysis and discussion of ethical concerns faced by HCWs during the Nipah outbreak in Kerala based on six principles of public health (1). Ethical issues are always debatable based on their contexts. The Nipah outbreak which was never before experienced by the state involved several knowledge gaps and ethical issues. Based on the WHO ethical principles of infectious disease outbreaks, the authorities' actions met certain ethical criteria but did not meet others.

Our analysis can be summarised as below:

- The distribution of resources and opportunities among HCWs was not based on equity, so the outcomes were different, hence, the principle of justice was not fully addressed.

- The basic needs of those HCWs in quarantine and society were provided for, so the principle of beneficence was met.

- By adapting a strategy of modified non-institutional quarantine (proportionality) and resuming hospital duties (efficiency) the principle of utility was met.

- Since the privacy and confidentiality of HCWs were not maintained and several experienced social boycott and stigma, the principle of respect for persons was not adequately met here.

- During and after the quarantine period, some HCWs' social and religious freedom was impaired due to social discrimination. Thus the principle of liberty was inadequately met. 
- The HCWs received proportional return for the exemplary services rendered through priority access to healthcare, appropriate remuneration, support for reintegrating into the community and assistance to family members - thus meeting the principle of reciprocity.

- The last principle of solidarity was met through the joint efforts made by the authorities, political and religious leaders and the community which was commendable.

The ethical lacunae should be understood and addressed in future outbreaks. Setting up decisionmaking systems and procedures in advance is the best way to ensure that ethically appropriate decisions will be made if an outbreak occurs in the future. Governments have an ethical obligation to ensure the longterm capacity of the systems necessary for effective epidemic prevention and response. The Nipah outbreak can be taken as a lesson for future outbreaks like the ongoing Covid-19 pandemic where quarantine remains the main strategy available for containment.

\section{References}

1. World Health Organization. Guidance for managing ethical issues in infectious disease outbreaks. Geneva:WHO; 2016 [cited 2020 June 21]. Available from: https://www.who.int/ethics/publications/infectiousdisease-outbreaks/en/

2. Krebs J. The importance of public-health ethics.Bull World Health Organ. 2008 Aug; 86 (8): 577-656.

3. Arunkumar G, Chandni R, Mourya DT, Singh SK, Sadanandan R, Sudan P, Bhargava B, Nipah Investigators People and Health Study Group. Outbreak investigation of Nipah virus disease in Kerala, India, 2018. J Infect Dis. 2019 Jun 15;219(12): 1867-78.
4. Yadav PD, Shete AM, Kumar GA, Sarkale P, Sahay RR, Radhakrishnan C, Lakra R. Nipah virus sequences from humans and bats during Nipah outbreak, Kerala, India, 2018. Emerg Infect Dis. 2019 May; 25(5):1003-06.

5. Sadanandan R, Arunkumar G, Laserson KF, Heretik KH, Singh S, Mourya DT, et al. Towards global health security: response to the May 2018 Nipah virus outbreak linked to Pteropus bats in Kerala, India. BMJ Glob Health. 2018 Nov 9; 3(6): e001086.

6. National Health Mission, Kerala. Encountering Nipah: The Kerala experience. Kozhikode, Kerala; NHM 2018-19. Available from: https:// arogyakeralam.gov.in/

7. Desclaux A, Badji D, Ndione AG, Sow K. Accepted monitoring or endured quarantine? Ebola contacts' perceptions in Senegal. Soc Sci Med. 2017 Apr; 178: 38-45.

8. Bai YM, Lin C-C, Lin C-Y, Chen J-Y, Chue C-M, Chou P. Survey of stress reactions among health care workers involved with the SARS outbreak. Psychiatr Serv. 2004 Sep; 55(9): 1055-57.

9. Lithin Z, Harikrishnan U, Jayakumar C, Sekar K. Psychosocial perspective of Nipah virus outbreak in Kerala, India. Int J Sci Stud. 2019 Feb; 6(11):15962.

10. Modjarrad K, Moorthy VS, Millett P, Gsell P-S, Roth C, Kieny MP. Developing global norms for sharing data and results during public health emergencies. PLOS Med. 2016 Jan 5; 13(1): e1001935.

11. Dye C, Bartolomeo K, Moorthy V, Kieny MP. Data sharing in public health emergencies: a call to researchers. Bull World Health Organ. 2016 Mar1; 94(3):158. doi: 10.2471/ BLT.16.170860

12. Wenzel N. Modeling the zoonotic transmission dynamics of Nipah virus: Implications for outbreak control and model- guided fieldwork. Public Health Theses. 2014; 1320 [cited 2020 Jun 22]. Available from: http:// elischolar.library.yale.edu/ysphtdl/1320

13. Becker L. Reciprocity, justice, and disability. Ethics. 2005 Oct; 116(1):9-39.

14. Swathy SS, Sidharthan M, Issudeen M, Shibukumar TM, Kumar A, Tharayil HM. Psychological interventions during Nipah viral outbreak in Kozhikode District, 2018. Indian J Psychol Med. 2018 Jul-Aug; 40 (4):3879.

15. Dawson A, Jennings B. The place of solidarity in public health ethics. Public Health Reviews. 2012; 34(1):65-79.

\section{IJME is indexed on Pubmed, Scopus \& TPI.}

Articles from $I J M E$, as also from the journal's previous titles Medical Ethics (1993-5), and Issues in Medical Ethics (1996-2003) are indexed on Pubmed. 